\title{
CD95/phosphorylated ezrin association underlies HIV-1 GP120/IL-2-induced susceptibility to CD95(APO-1/Fas)-mediated apoptosis of human resting $\mathrm{CD} 4^{+} \mathrm{T}$ lymphocytes
}

\author{
F Luciani ${ }^{1}$, P Matarrese ${ }^{2}$, AM Giammarioli ${ }^{2}$, L Lugini ${ }^{1}$, \\ F Lozupone $^{1}$, C Federici ${ }^{1}$, E lessi ${ }^{1}$, W Malorni ${ }^{2}$ and S Fais ${ }^{\star, 1}$ \\ 1 Laboratories of Immunology, Istituto Superiore di Sanità, 00161 Rome, Italy \\ 2 Laboratories of Ultrastructures, Istituto Superiore di Sanità, Viale Regina \\ Elena, 299, 00161 Rome, Italy \\ * Corresponding author: S Fais, Laboratory of Immunology, Istituto Superiore di \\ Sanità, Viale Regina Elena, 299, 00161 Rome, Italy. Tel: 396.49903195/ \\ 396.49902455; Fax: 396.49387115; E-mail: Fais@ iss.it
}

Received 19.6.03; revised 17.9.03; accepted 27.10.03; published online 23.1.04 Edited by JC Ameisen

\begin{abstract}
CD95(APO-1/Fas)-mediated apoptosis of bystander uninfected T cells exerts a major role in the HIV-1-mediated CD4 + T-cell depletion. HIV-1 gp120 has a key role in the induction of sensitivity of human lymphocytes to CD95-mediated apoptosis through its interaction with the CD4 receptor. Recently, we have shown the importance of CD95/ezrin/actin association in CD95mediated apoptosis. In this study, we explored the hypothesis that the gp120-mediated CD4 engagement could be involved in the induction of susceptibility of primary human $\mathrm{T}$ lymphocytes to CD95-mediated apoptosis through ezrin phosphorylation and ezrin-to-CD95 association. Here, we show that gp120/LL-2 combined stimuli, as well as the direct CD4 triggering, on human primary $\mathrm{CD} 4^{+} \mathrm{T}$ lymphocytes induced an early and stable ezrin activation through phosphorylation, consistent with the induction of ezrin/CD95 association and susceptibility to CD95-mediated apoptosis. Our results provide a new mechanism through which HIV-1-gp120 may predispose resting $\mathrm{CD}^{+}{ }^{+} \mathrm{T}$ cell to bystander CD95-mediated apoptosis and support the key role of ezrin/CD95 linkage in regulating susceptibility to CD95-mediated apoptosis. Cell Death and Differentiation (2004) 11, 574-582.

doi:10.1038/sj.cdd. 4401374

Published online 23 January 2004
\end{abstract}

Keywords: CD95; ezrin; HIV-1-gp120; cytoskeleton; phosphorylation

Abbreviations: AIDS, acquired immunodeficiency syndrome; HIV-1, human immunodeficiency virus type 1; IL2, interleukin-2; Tyr, tyrosine; P-Tyr, phospho-tyrosine; SEM, scanning electron microscopy

\section{Introduction}

CD95 (APO-1/Fas) is a member of the tumor-necrosis factor receptor family involved in both the physiological control of cell proliferation and in the pathogenesis of viral, autoimmune and neoplastic diseases. ${ }^{1-4}$ However, little is known about the mechanisms underlying cell susceptibility to the CD95mediated apoptosis. Apoptosis of bystander uninfected $T$ cells holds a major role in the human immunodeficiency virus type 1 (HIV-1)-mediated CD4 ${ }^{+}$T-cell depletion ${ }^{5-8}$ through mechanisms that may involve increased sensitivity of human lymphocytes to CD95-mediated apoptosis. ${ }^{9-11}$ In fact, HIV-1 gp120 has been shown to be involved in the induction of increased sensitivity to CD95-mediated apoptosis through triggering of CD4 receptor and CXCR4 or CCR5 signaling events (reviewed in Roshal et al. ${ }^{6}$, Vlahakis et al. ${ }^{11}$ ). Moreover, the state of activation/differentiation and/or polarization of human lymphocytes is a crucial factor in the pathogenesis of HIV-1 infection, including the induction of apoptotic pathways. ${ }^{12-23}$ During activation, $T$ lymphocytes become motile cells, switching from a spherical to a polarized shape and rapidly orienting their cytoskeletal and membrane components towards the polarized cell site (i.e. the uropod or the leading edge). ${ }^{24-29}$ The ability of a cell to polarize is directly related to the membrane/cytoskeleton interactions. Ezrin, radixin and moesin belong to a family of proteins (ERM) involved in the linking of transmembrane proteins to the actin cytoskeleton. ${ }^{30-35}$ ERM proteins expose their binding sites to both actin and membrane proteins exclusively when they are in an opened/activated form through phosphorylation. ${ }^{35-36}$ Notably, a rapid ezrin Tyr-phosphorylation does occur following CD4 crosslinking in human T-lymphocytes. ${ }^{37}$ Ezrin is a substrate for Lck in T cells ${ }^{38}$ and the CD4 engagement by HIV-1 gp120 is able to activate several tyrosine (Tyr) kinases ${ }^{39-40}$ including Lck. ${ }^{41}$ Moreover, ezrin binding to membrane proteins is involved both in lymphocyte activation and in the formation of the immunological synapse. ${ }^{42}$ Connection to actin is of crucial importance in CD95-mediated apoptosis, both in predisposing $\mathrm{T}$ lymphocytes to CD95mediated apoptosis, ${ }^{43}$ and in allowing the early steps of CD95 signaling. ${ }^{44}$ Particularly, we have shown that the CD95 polarization, due to the ezrin-mediated CD95/actin association, is the key in rendering human $\mathrm{CD}^{+} \mathrm{T}$ lymphocytes susceptible to CD95-mediated apoptosis. ${ }^{43}$

In this study, the possible involvement of ezrin activation and ezrin/CD95 association in the HIV-1 gp120-induced susceptibility to CD95-mediated apoptosis of human resting $\mathrm{CD} 4{ }^{+} \mathrm{T}$ lymphocytes was investigated.

\section{Results}

\section{Ezrin phosphorylation in CD95-mediated apoptosis susceptible T cells}

In this first set of experiments, we investigated the involvement of ezrin phosphorylation in the susceptibility to 
CD95-mediated apoptosis of human lymphocytes. Our previous report ${ }^{43}$ showed that CD95 polarized and associated to ezrin only in human lymphocytes susceptible to CD95mediated apoptosis (i.e. CEM cells and day- 6 activated T lymphocytes). Thus, we analyzed CEM cells and activated primary human $\mathrm{T}$ lymphocytes in order to verify whether ezrin was stably phosphorylated in these conditions. For this purpose, we tested the presence of phosphorylated ezrin by blotting with an anti-phosphotyrosine (P-Tyr) monoclonal antibody on ezrin immunoprecipitates from CEM cells and resting (analyzed immediately after isolation) or day- 6 activated T-lymphocytes total protein extracts. The results showed detectable P-Tyr levels exclusively in ezrin immunoprecipitates of CEM and day- 6 activated T cells (Figure 1a), that is in cells displaying susceptibility to CD95-mediated apoptosis. Thus, we analyzed the effects of activation on ezrin phosphorylation and CD95-mediated apoptosis cell susceptibility on purified CD4 $+\mathrm{T}$ cell populations (97\% purity) (Figure 1b). We obtained results highly consistent to those obtained on peripheral blood lymphocytes (PBLs). In fact, $\mathrm{P}$-Tyr levels were exclusively detectable in ezrin immunoprecipitates of CEM and day- 6 activated CD4 + T cells (Figure 1b, left panel). Moreover, day- 6 activated CD4 + T cells showed a susceptibility to CD95-mediated apoptosis that was fully comparable to that shown for day- 6 activated $T$ cells (Figure 1b, right panel). These results suggested that ezrin Tyr-phosphorylation may represent a prerequisite for CD95ezrin interaction and, as a consequence, for susceptibility to CD95-mediated apoptosis.

\section{Gp120/rlL-2 stimuli induced ezrin phosphorylation}

On the basis of previous reports, ${ }^{38-42}$ we analyzed the capability of HIV-1 gp120-CD4 binding to trigger ezrin Tyrphosphorylation in T lymphocytes (Figure 1c-d). The total cell extracts of PBLs treated with gp120 and/or recombinant IL2 were immunoprecipitated using an anti-ezrin $\mathrm{mAb}$ and blotted with an anti P-tyr mAb, in order to test the presence of the Tyrphosphorylated form of ezrin. The analysis was performed at both early (Figure 1c) and late (Figure 1d) time points after the single and combined treatments. At the early time points (2-30 min), exclusively the combined IL2/gp120 treatment induced a Tyr-phopshorylation of ezrin, lasting until $30 \mathrm{~min}$ after stimulation, while a very early but unstable ezrin Tyrphosphorylation followed either the single gp120 or IL2 treatments (Figure 1c). Thus, we performed the same analysis on gp120- and/or IL2-treated PBLs, 24 or $48 \mathrm{~h}$ after stimulation. The results showed again that only human primary PBLs collected at both 24 and $48 \mathrm{~h}$ IL2/gp120 posttreatment displayed a strong Tyr-phosphorylation of ezrin (Figure 1d), while the single treatments resulted in an almost undetectable phosphorylation of ezrin. Notably, the results showed that under the combined treatment, $T$ lymphocytes maintained a level of ezrin Tyr-phosphorylation comparable to CEM cells and day- 6 activated PBLs (Figure 1d). Monocyte-depleted purified CD4 $+\mathrm{T}$ cells behaved as PBLs, allowing us to exclude that a triggering of CD4 + monocytes significantly contributed to the increase of ezrin phosphorylation detected after gp120 stimulation of the total PBL (not shown). These results suggested that the contemporary

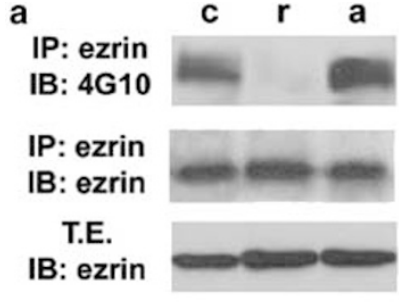

b

\section{IP: ezrin \\ IB: $\mathbf{4 G 1 0}$ \\ IP: ezrin \\ IB: ezrin}

T.E.

IB: ezrin

$$
\text { c } r \text { a } \mathrm{m}
$$
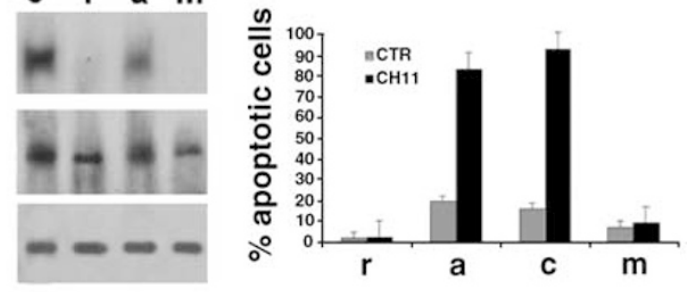

C

\section{IP: ezrin \\ IB: 4 G10}

IP: ezrin

IB: ezrin

T.E.

IB: ezrin

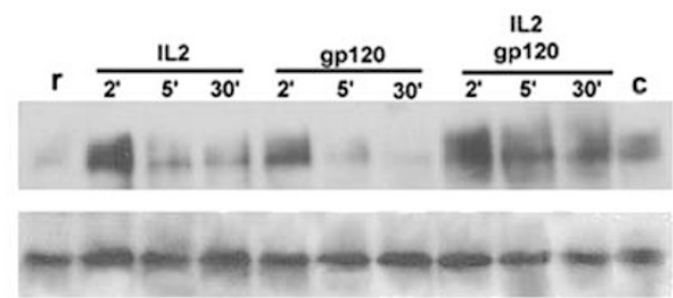

d

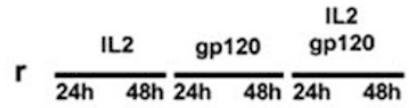

IP: ezrin

IB: $\mathbf{4 G 1 0}$

IP: ezrin

IB: ezrin

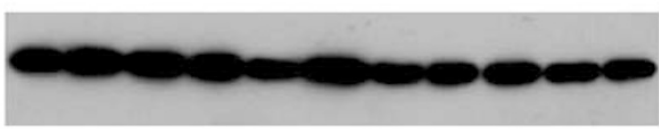

T.E. IB: ezrin

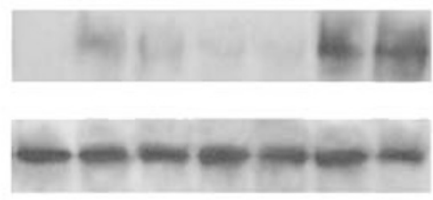

Figure 1 Analysis of ezrin phosphorylation. (a) Ezrin phosphorylation in cells susceptible to CD95-mediated apoptosis. Total protein extracts (TE) from CEM cells (c), resting ( $r$ ) and day- 6 activated (a) PBLs were or not immunoprecipitated (IP) with anti-ezrin $m A b$, and immunoblotted (IB) with anti-ezrin or anti-P-Tyr mAb. To note the expression of P-Tyr-ezrin only in cells susceptible to CD95apoptosis (i.e. CEM cells and day-6 activated PBLs). (b) Left panel: ezrin phosphorylation in purified CD4 $+\mathrm{T}$ cells susceptible to CD95-mediated apoptosis. Total protein extracts (TE) from CEM cells (c), resting (r), day- 6 activated (a) CD4 $+\mathrm{T}$ cells and $\mathrm{CD} 4+$ monocytes $(\mathrm{m})$ were or not immunoprecipitated (IP) with anti-ezrin $\mathrm{mAb}$, and immunoblotted (IB) with antiezrin or anti-P-Tyr mAb. Right panel: FACS analysis of CD95-mediated apoptosis susceptibility of purified CD4 $+\mathrm{T}$ cells after ant-CD95 triggering (using $\mathrm{CH} 11 \mathrm{mAb})$. (c) Early $(2 \mathrm{~min}, 5 \mathrm{~min}, 30 \mathrm{~min})$ and (d) late $(24 \mathrm{~h}, 48 \mathrm{~h})$ phosphorylation of ezrin in IL2, gp120 or IL2 plus gp120 treated PBLs. Resting (r) PBLs and CEM cells (c) were used as negative and positive controls, respectively. The results showed that only PBLs after IL2/gp120 combined treatment displayed strong and long-lasting ezrin phosphorylation 
gp120 and IL2 triggering is able to sustain and maintain a high level of ezrin activation in human resting PBLs, which was comparable to that of human lymphoblastoid T cells and day 6 activated PBLs. Notably, different from both lymphoblastoid T cells and day- 6 activated PBLs, the gp120/IL-2 stimulation was able to induce stable ezrin phosphorylation in human resting lymphocytes in the absence of cell proliferation. In fact, cell cycle analyses clearly indicated that no significant differences could be detected between the resting and IL-2treated PBLs (resting cells: $89.36 \%$ G0G1; $2.53 \%$ S; $8.11 \%$ G2M; IL2-treated cells: 88.5 G0G1; 1.96 S; 9.52 G2M).

\section{Combined gp120/rlL-2 stimuli induced polarization of CD95 on uropods}

Thus, we investigated the effects of HIV-1 gp120/IL2 treatments on the cellular polarization of $\mathrm{T}$ lymphocytes. For this purpose, we firstly performed scanning electron microscopy (SEM) analysis on IL2 and/or HIV-1 gp120-treated primary human $\mathrm{T}$ cells. The results showed that, consistent with the induction of ezrin activation/phosphorylation, exclusively the gp120/IL2 combined treatment induced pseudopods/uropods formation (Figure 2a, right lower panel) in up to $70 \%$ of lymphocytes, as compared to both controls (Figure $2 \mathrm{a}$, left upper panel) and the single IL2 (Figure 3a, right upper panel) or gp120 treatments (Figure 2a, left lower panel). Consistent with electron microscopy analysis, immunofluorescence experiments showed again that only the combined gp120/IL2 treatment of $\mathrm{T}$ lymphocytes induced uropods formation, CD95 and ezrin polarization and CD95/ezrin colocalization on these structures (Figure $2 \mathrm{~b}$, lower panels), as compared to the untreated lymphocytes (Figure $2 \mathrm{~b}$, upper panels) and lymphocytes that underwent single treatments (Figure 2b, central panels). These results were confirmed in experiments performed with purified CD4 $+\mathrm{T}$ cells (data not shown).

\section{Gp120/rlL-2 stimuli induced CD95/ezrin association}

Polarization of a membrane protein and its colocalization with a protein of the ERM family are the first and more important features suggesting a possible molecular association to the actin cytoskeleton. Thus, in the following set of experiments, we verified whether a CD95/ezrin association underlined CD95/ezrin colocalization induced by gp120/IL2 combined stimuli. For this purpose, we performed coimmunoprecipitation and Western blot analysis on gp120/IL2 pretreated $\mathrm{T}$ lymphocytes, as compared to the other treatments. The results (Figure 3a) showed that CD95 and ezrin coimmunoprecipitated only in extracts from IL2/gp120-treated $\mathrm{T}$ lymphocytes, while ezrin was undetectable in the CD95 immunoprecipitates from extracts of single treatments.

Thus, we performed new immunoprecipitation experiments aimed at defining the phosphorylation state of ezrin associated to CD95. For this purpose, we immunoblotted with either an anti-P-Tyr mAb or an anti-ezrin mAb the CD95 immunoprecipitates from CEM, 6 days activated PBLs, gp120/IL2-treated or resting PBLs. The results showed the presence of an $80 \mathrm{kDa}$ Tyr-phosphorylated protein in CD95 immunoprecipitates of CEM cells, 6 days activated PBLs and gp120/IL2-treated PBLs (Figure 3b). Reblotting the same nitrocellulose filter with anti-ezrin $\mathrm{mAb}$ confirmed that the phosphorylated $80 \mathrm{kDa}$ protein band fully overlapped with ezrin band (Figure 3b). Notably, in CD95 immunoprecipitates of resting PBLs, we did not detect both an $80 \mathrm{kDa}$ Tyrphosphorylated protein and the ezrin protein (Figure $3 \mathrm{~b}$ ), supporting the specificity of our findings. This set of results strongly suggested that the phosphorylated form of ezrin was associated with CD95 exclusively in lymphocytes susceptible to CD95-mediated apoptosis and in those treated with gp120/ IL2, in turn supporting a role of Tyr-phosphorylation-mediated ezrin activation in CD95/ezrin association.

\section{Gp120/rIL-2 stimuli induced susceptibility to CD95-mediated apoptosis}

Our previous data showed that in human lymphocytes, CD95/ ezrin polarization, colocalization and association were consistent with susceptibility to CD95-mediated apoptosis. ${ }^{43}$ Thus, we analyzed the response of gp120/IL2 pretreated T lymphocytes to CD95 triggering, in order to assess whether CD95 polarized relocalization and association with ezrin corresponded to susceptibility to CD95-mediated apoptosis. FACS analysis (Figure 3c) showed that only gp120/IL2 pretreated human lymphocytes displayed an increased (twoto three-fold) susceptibility to CD95-mediated apoptosis, induced by a specific CD95-triggering-mAb (Figure 3c, right panel), while the single-, gp120- or IL2-treated lymphocytes did not show a detectable increase in the capability to undergo apoptosis (Figure 3c, right upper and central panels).

Again, these results support the importance of CD95/ezrin association in the induction of CD95-mediated apoptosis susceptibility and suggest a key role for gp120-induced ezrin activation in the establishment of an enhanced susceptibility to CD95-mediated apoptosis of uninfected T lymphocytes.

\section{Ezrin phosphorylation through specific CD4 triggering}

Antibody-mediated engagement of CD4 induces sensitization to CD95-mediated apoptosis in resting purified T cells. ${ }^{45}$ Hence, in order to verify whether a specific CD4 receptor triggering underlay the HIV-1 gp120-induced ezrin phosphorylation, ezrin/CD95 association and susceptibility to CD95mediated apoptosis, we treated resting CD4 + T cells with an anti-CD4 antibody, either alone or in combination with IL2, verifying whether this stimulation might mimic the gp120/IL2 effect.

CD4 + purified T cells were treated with the triggering antiCD4 mAb for $48 \mathrm{~h}$, either alone or in the presence of IL2, and analyzed for CD95-mediated susceptibility to apoptosis (Figure $4 a$ and b), as well as for the presence of ezrin phosphorylation and ezrin/CD95 association (Figure 4c). The $48 \mathrm{~h}$ treatment of CD4 $+\mathrm{T}$ cells with the anti-CD4-triggering $\mathrm{mAb}$ was highly effective in inducing proneness to CD95mediated apoptosis (Figure 4a), either alone or in the presence of IL2, which only slightly increased the effect of 
a
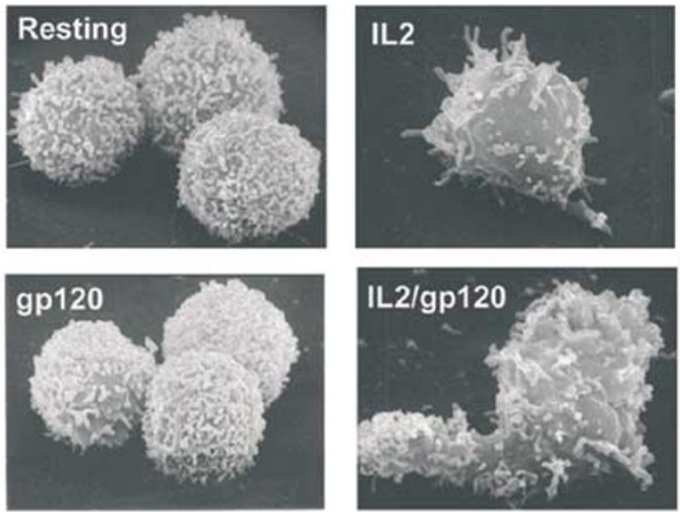

b

ezrin
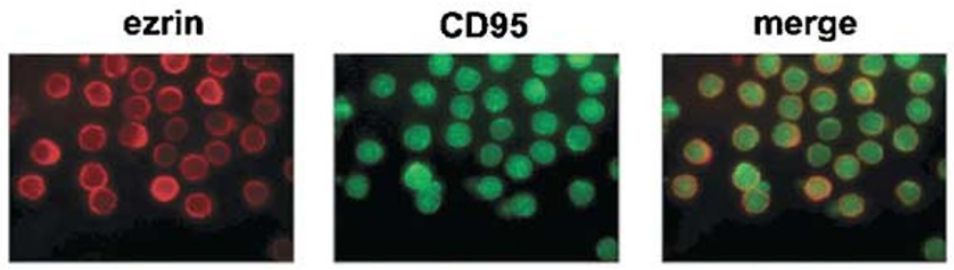

IL2
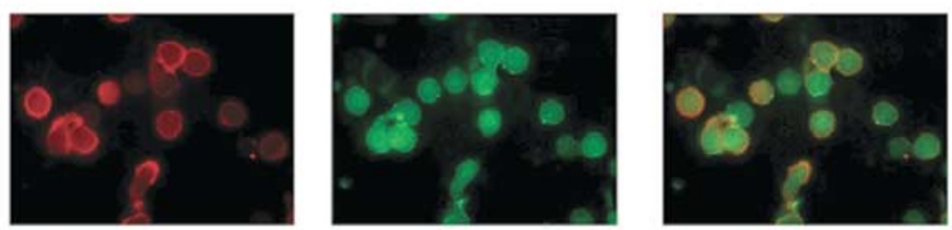

gp120
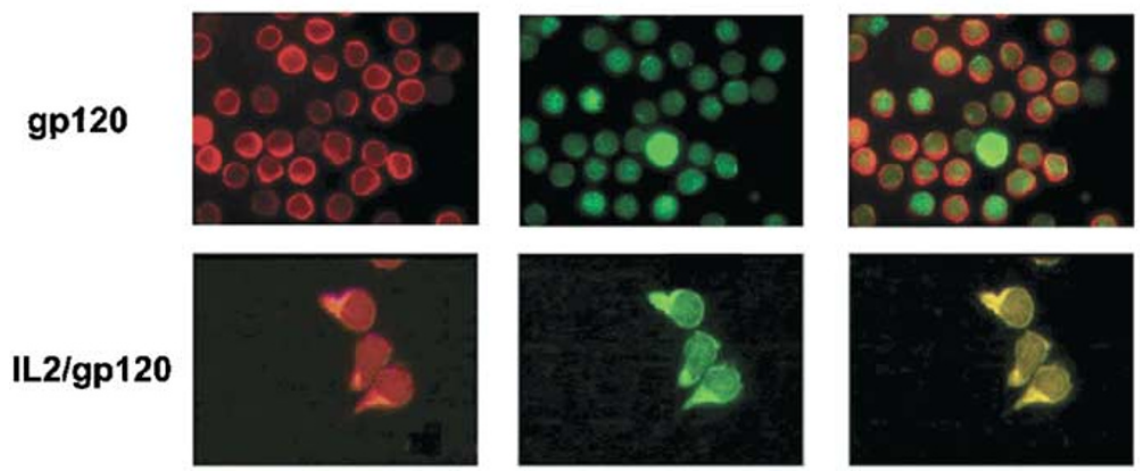

Figure 2 Effects of gp120//L2 $48 \mathrm{~h}$ combined treatment on CD95 polarization and colocalization/association with ezrin. (a) SEM analysis showed that gp120/IL2 combined treatment clearly induced morphological changes of PBLs, resulting in uropod formation (lower right panel). Uropods are not detectable in single IL2- or gp120treated and in resting PBLs (magnification $\times 3000$ ). (b) Immunofluorescence analysis showed CD95 and ezrin polarization (lower left and central panels) and CD95/ ezrin colocalization (lower right panel) exclusively in gp120/L2-treated PBLs, while single treated (central panels) and untreated cells (upper panels) did not show any feature of CD95 and ezrin polarization or colocalization (magnification $\times 1200$ )

the anti-CD4 mAb treatment on the susceptibility to CD95mediated apoptosis. This was clear even when the percentages of cells undergoing secondary necrosis (propidium iodide (PI) positive) were added up to the apoptotic cells (annexin V positive) (Figure 4b). Consistent with the susceptibility to the CD95 triggering, the anti-CD4 mAb treatment induced ezrin phosphorylation (Figure 4c, upper panel) and ezrin/CD95 association in the purified CD4 + T cells in the purified CD4 + T cells (Figure 4c, lower panel). Notably, the results obtained with the anti-CD4 antibody were fully comparable to those obtained with the gp120/IL-2 stimulation of purified CD4 $+\mathrm{T}$ lymphocytes. This set of results on the one hand confirm previous results showing that CD4 receptor triggering alone is able to induce ezrin phosphorylation, ${ }^{37}$ and on the other newly demonstrate that ezrin phosphorylation is an early step of a cascade of events including ezrin/CD95 association and sensitization to CD95-mediated apoptosis, which may involve a direct stimulation of CD4 receptor.

\section{Discussion}

The actin cytoskeleton participation in both the CD95 signaling pathway and the CD95-induced apoptosis has been proposed. ${ }^{43-46}$ An ezrin-mediated CD95 connection to actin has a role in predisposing $\mathrm{T}$ lymphocytes to CD95-mediated 
a

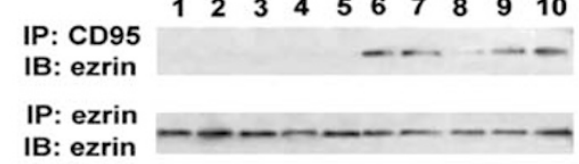

b

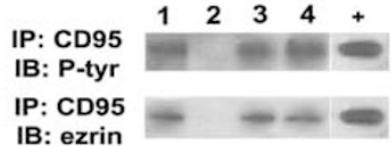

C
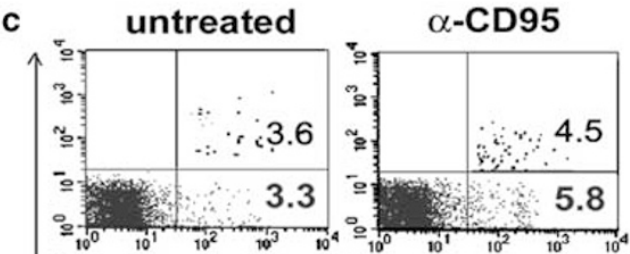

resting
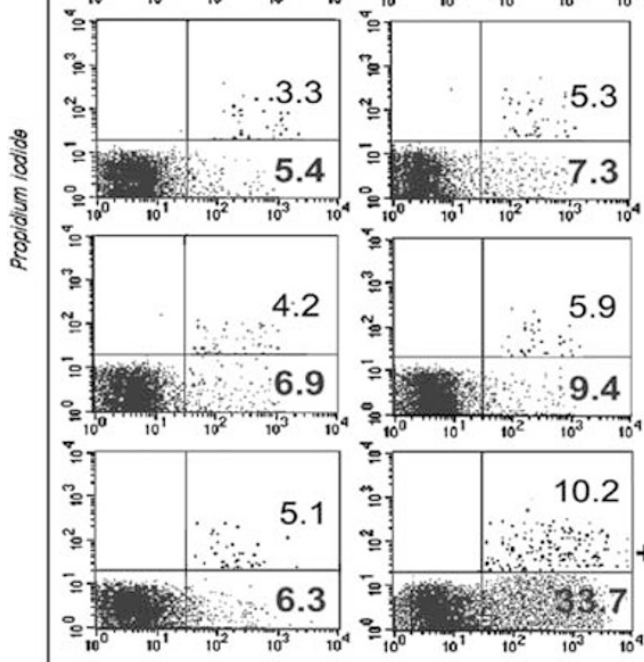

+IL2

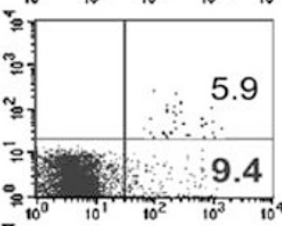

$+\operatorname{gp} 120$

Annexin $v F f T C$

Figure 3 Effects of gp120/L2 combined treatment on CD95/ezrin association and CD95-mediated apoptosis susceptibility. (a) Total extracts from PBLs were immunoprecipitated (IP) with an anti-CD95 mAb and immunoblotted (IB) with an anti-ezrin mAb; (1) resting PBLs; (2) 24h IL2-treated PBLs; (3) $48 \mathrm{~h}$ IL2-treated PBLs; (4) $24 \mathrm{~h}$ gp120-treated PBLs; (5) 48h gp120-treated PBLs; (6) 24h IL2/ gp120-treated PBLs; (7) 48 IL2/gp120-treated PBLs; (8) 24h IL2/PHA-treated PBLs; (9) 6 days IL2/PHA-treated PBLs; (10) CEM cells. Note that ezrin coimmunoprecipitates with CD95 only in cells susceptible to CD95 apoptosis (CEM cells and day- 6 activated PBLs) and in IL2/GP120-treated cells. (b) Total extracts from PBLs were immunoprecipitated (IP) with an anti-CD95 mAb and immunoblotted (IB) with an anti-P-Tyr or an anti-ezrin $\mathrm{mAb}$, as appropriate. Lanes correspond, respectively, to: (1) CEM cells; (2) resting PBLs; (3) 6 days IL2/PHAtreated PBLs; (4) $48 \mathrm{~h} \mathrm{IL2/gp120-treated} \mathrm{PBLs;} \mathrm{(TE)} \mathrm{Total} \mathrm{protein} \mathrm{extracts} \mathrm{from}$ CEM cells immunoblotted with anti-ezrin $\mathrm{mAb}$. The upper panel shows the presence of a Tyr-phosphorylated protein band in CD95 coimmunoprecipitates corresponding to the ezrin band $(80 \mathrm{kDa})$ detectable in the CEM total extracts. The lower panel shows an immunoblotting with an anti-ezrin $m A b$ in the same nitrocellulose filter, after stripping. Notably, the ezrin bands detected fully overlapped Tyr-phosphorylated protein bands, strongly suggesting the presence of phosphorylated ezrin in CD95 immunoprecipitates. (c) Flow cytometric analysis of T lymphocytes after the double staining procedure with annexinV-FITC/PI performed on living cells. In the lower right quadrant (annexinV single positive) and in the upper right quadrant (annexinV/propidium double positive) of all the pictures the percentages of cells in early or late apoptosis are represented, respectively. Percentage of apoptosis was obtained by flow cytometric analysis of human primary lymphocytes after a three-color staining procedure with annexin V-FITC/PI/ CD4PerCP performed on living cells. IL2, gp120, IL2/gp120 48 h treated or untreated PBLs (as indicated) were left untreated (left column, controls) or stimulated for $48 \mathrm{~h}$ with an anti-CD95-triggering $\mathrm{mAb}$ (clone $\mathrm{CH} 11)$. Apoptosis was analyzed in electronically gated $\mathrm{CD} 4^{+}$cells only $(65 \pm 4 \%)$ apoptosis $^{43}$ and the CD95 connection to actin is a crucial requirement for the occurrence of the early events of the CD95 signaling. ${ }^{44}$ However, there were no data supporting a possible role of this mechanism in the pathogenesis of CD95-mediated apoptosis of human diseases. Infection with HIV-1 is associated with a progressive decrease in CD4 + $\mathrm{T}$-cell number and a consequent impairment in host immune defense. The mechanism by which the virus depletes CD4+ $\mathrm{T}$ cells, however, is not clearly understood. Since the virus predominantly infects CD4 + lymphocytes in vivo, some have assumed that HIV replication directly kills the infected cells or that the anti-HIV immune response destroys them. However, a large number of studies do not support this concept (reviewed in Roshal et al. ${ }^{6}$ ), suggesting that CD4+ $\mathrm{T}$ lymphocyte depletion occurs by an indirect mechanism. ${ }^{47}$ The most plausible mechanism, which is backed by in vivo data, involves the consequences of HIV contact with resting CD4 + T lymphocytes, which cannot support virus replication. ${ }^{47}$ Notably, CD4 + T cells not making HIV are the predominant cells dying in the lymph nodes of HIV + subjects. ${ }^{47}$ These studies indicate that the principal mechanism of CD4 + T-cell depletion by HIV is due to its use of CD4 as its primary receptor and the signaling induced through this receptor in nonpermissive (resting) T lymphocytes. ${ }^{47}$ Analysis of $T$ cells from patients infected with HIV, or of T cells infected in vitro with HIV, demonstrates a significant fraction of both infected and uninfected cells dying by apoptosis. ${ }^{48}$ Between the many mechanisms that contribute to HIV-associated lymphocyte apoptosis, gp120/160 binding to the CD4 receptor is enclosed (reviewed in Roshal et al. ${ }^{6}$ ). On the basis of our previous report ${ }^{43}$ in this study, we have explored the possibility that HIV-1-induced proneness to apoptotic mechanisms could be due to the gp120-mediated ezrin activation, and ezrin-to-CD95 association, in human resting $T$ cells. Previous studies showed that ezrin Tyr-phosphorylation is a crucial requirement for the ezrin linkage to the majority of the known ezrin-interacting membrane proteins (e.g. ICAMs, CD44). ${ }^{35,49-53}$ In this study, we have shown that ezrin Tyr-phosphorylation was a constant finding in both CEM cells and day -6 activated T lymphocytes, which are cells where the consistency of CD95-ezrin association and susceptibility to CD95-mediated apoptosis have been previously shown. ${ }^{43}$ When we treated primary $\mathrm{T}$ cells with gp120 and IL-2, the resulting data showed clearly that gp120-IL-2 stimuli induced (i) lymphocyte polarization with uropod formation; (ii) CD95/ezrin colocalization on lymphocyte uropods and (iii) a stable ezrin phosphorylation, with the presence of an $80 \mathrm{kDa}$ Tyr-phosphorylated protein, corresponding to ezrin, in CD95 immunoprecipitates. All these acquired properties were consistent with susceptibility to CD95-mediated apoptosis. Notably, the interaction of virionassociated gp120 with cell surface CD4 can occur in uninfected cells. ${ }^{54}$ Specifically, gp120/gp41 complexes on infected cells may interact with receptor molecules expressed on uninfected cells. The gp120/CD4 interaction may lead both to sensitization of T cells to CD95-mediated apoptosis ${ }^{55}$ and activation induced T-cell death. ${ }^{56}$ Moreover, gp120 protein shed from both infected cells and HIV-1 virions may bind to uninfected CD4 + T cells and gp120 can by itself transduce intracellular signals. ${ }^{57}$ These signals are thought to be 
a
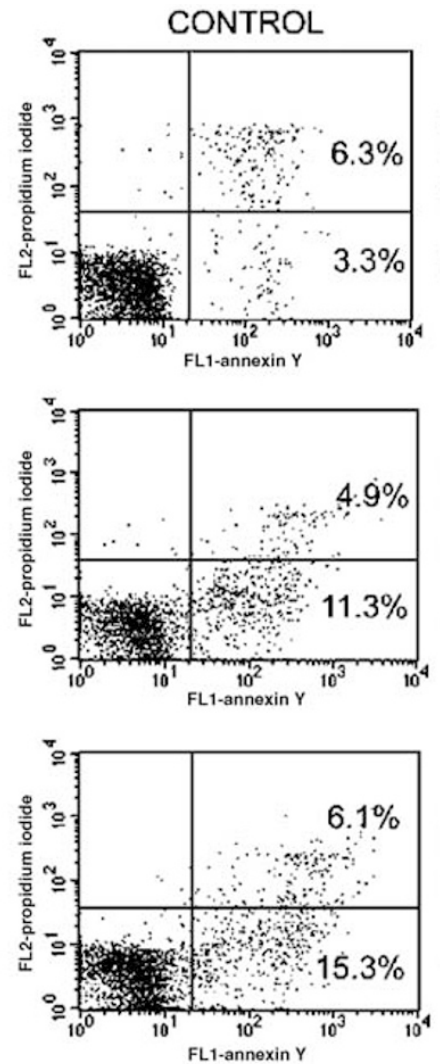

b

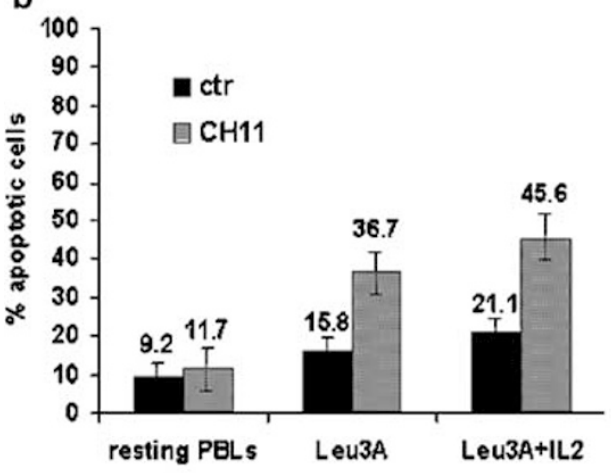

+ a-CD95

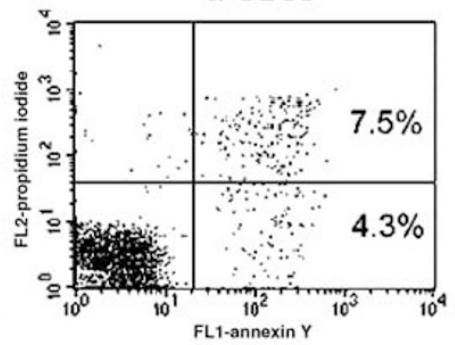

resting
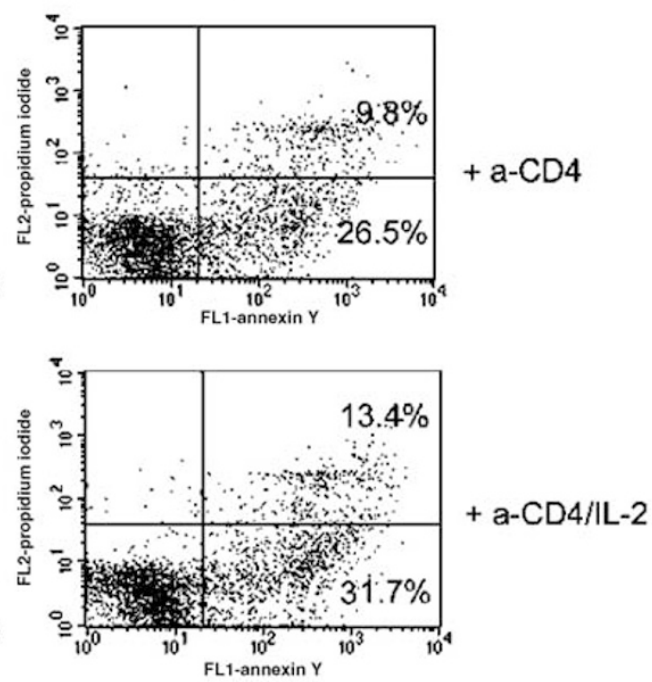

C $\quad \begin{array}{lllll} & 1 & 2 & 3 & 4\end{array}$

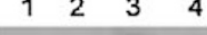

$75 \mathrm{kDa}$

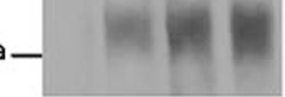

P: ezrin

IB: P-Tyr

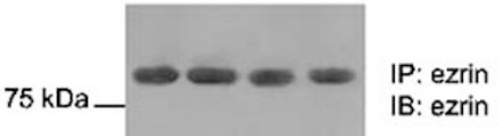

IB: ezrin

IP: ezrin

IB: CD95

Figure 4 Effects of CD4 triggering on ezrin phosphorylation, CD95/ezrin association and CD95-mediated apoptosis susceptibility. (a) Flow cytometric analysis of T lymphocytes after a double staining procedure with annexinV-FITC/PI performed on living cells. In the lower right quadrant (annexinV single positive) and in the upper right quadrant (annexinV/propidium double positive) of all the pictures the percentages of cells in early or late apoptosis are represented, respectively. Percentage of apoptosis was obtained by flow cytometric analysis of human primary purified CD4 + T lymphocytes after a double color staining procedure with annexin V-FITC/PI performed on living cells. Anti-CD4 (a-CD4), anti-CD4/LL-2 (a-CD4/LL-2) $48 \mathrm{~h}$ treated or resting purified CD4 + T lymphocytes (as indicated) were left untreated (left column, controls) or stimulated for $48 \mathrm{~h}$ with an anti-CD95-triggering mAb (clone $\mathrm{CH} 11$ ). (b) Cells treated for $48 \mathrm{~h}$ as indicated in figure were tested for $\mathrm{CD} 95 \mathrm{apoptosis}$ susceptibility, via CH11 mAb triggering and subsequent FACS analysis of apoptotic cells (Annexin V/PI). Histograms show means + S.D. of three independent experiments. (c) Total extracts from CD4 + T lymphocytes were immunoprecipitated (IP) with an anti-ezrin mAb and immunoblotted (IB) with an anti-P-Tyr mAb (upper panel), an anti-ezrin mAb (central panel) or an anti-CD95 pAb (lower panel). (1) Resting CD4 + T lymphocytes; (2) 48 h Leu3A-treated CD4 + T lymphocytes; (3) $48 \mathrm{~h}$ Leu3A/IL2-treated CD4 + T lymphocytes; (4) CEM cells (positive control). Arrow indicates the $45 \mathrm{kDa}$ CD95 band, clearly distinguishable from $50 \mathrm{kDa}$ immunoprecipitating Ig heavy chain band. Notably, ezrin is phosphorylated and coimmunoprecipitated with CD95 (panel a) only in Leu3A- or Leu3A/L2-treated CD4 + T lymphocytes, namely in cells undergoing stimuli able to trigger susceptibility to CD95-mediated apoptosis, (panel b)

mediated via interactions of the HIV-1 envelope with CD4 receptor. ${ }^{57}$ In fact, we have shown here that all the effects obtained using unpurified PBLs or total T cells can be obtained in purified CD4 + T cells both with IL-2/gp120 combined stimuli and with direct triggering of CD4 receptor with an antiCD4 mAb.

In our study, resting lymphocytes and lymphocytes undergoing single gp120 or IL-2 stimulation did showed neither 
detectable polarization nor CD95/ezrin association or proneness to CD95-mediated apoptosis. These findings support the hypothesis that the state of activation of the immune system, instead of the HIV-1 infection, is the major cause of CD4+ depletion and AIDS ${ }^{6,23,47}$ In fact, we have shown that it is the contemporary gp120 and IL-2 stimulation that predisposes T lymphocytes to CD95-mediated apoptosis through ezrin phosphorylation, while the single treatments were not able to both sustain a lasting ezrin phosphorylation and to induce susceptibility to CD95-mediated apoptosis. Our data suggest in turn that the gp120/IL-2 stimulation induces proneness to CD95-mediated apoptosis through a peculiar activation state of T lymphocytes in the absence of the mitogenic stimuli.

Altogether, the results of this study provide a new mechanism through which HIV-1 may predispose T lymphocytes to CD95-mediated apoptosis, in turn favoring a CD4 + T lymphocyte apoptosis without infection. Particularly, with our results we provide evidence that the CD95/ezrin linkage is not only a key mechanism possibly involved in the physiological homeostasis of the immune system but also it may occur in a pathological condition, such as AIDS, where the pathogenic mechanism/s underlining the major cause of the disease, that is CD4 + T-cell depletion, were so far not clear.

\section{Materials and Methods}

\section{Cells and reagents}

All the cells used in this study were cultured in RPMI 1640 medium enriched with $10 \%$ fetal bovine serum and antibiotics (basic medium, BM), in humified $5 \% \mathrm{CO}_{2}$ and $95 \%$ air atmosphere. Human peripheral blood lymphocytes (PBLs) were obtained by Ficoll followed by Percoll density gradient centrifugation (CHEBIOS). Alternatively, CD4 $+\mathrm{T}$ cells were negatively selected by Magnetic Cell Sorting (MACS ${ }^{\mathbb{R}}$, Myltenyi biotec) from PBMC after Ficoll density gradient centrifugation, following the manufacturer's instructions. The kit allowed the depletion of B cells, monocyte, NK cells, cytotoxic T cells, dendritic cells early erythroid cells platelets and basophils from PBMC using a cocktail of CD8, CD11b, CD16, CD19, CD36 and CD56 antibodies. The percentage of CD4 + T cells obtained by this method was comprised between 96 and $99 \%$, as assessed by FACS analysis (see below). Purified T cells were analyzed immediately after isolation (resting $T$ cells) or, alternatively, activated with IL-2 $50 \mathrm{UI} / \mathrm{ml}$ (Chiron) and PHA $2 \mu \mathrm{g} / \mathrm{ml}$ (activated T cells). After 3 days from activation, PHA was removed and PBL were cultured until 7 days from activation in a medium supplemented again only with IL2 $60 \mathrm{U} / \mathrm{ml}$. Alternatively, cells were treated with IL-2 and/or HIV-1 gp120 $(3 \mu \mathrm{g} / \mathrm{ml}$, Intracell Corporation, USA) or anti-CD4 mAb (clone Leu3A, BD Biosciences) for the time indicated in the figures.

\section{Antibodies}

Western blotting: For ezrin detection, we used a monoclonal antibody supplied from SIGMA (clone 3C12). For pTyr detection, we used a monoclonal antibody supplied from Upstate Biotechnologies (clone 4G10). For CD95 detection, we used a polyclonal antibody supplied from SantaCruz, CA (clone C20).

Immunoprecipitation: Immunoprecipitation of Ezrin and CD95 was performed using a monoclonal antibody supplied from SIGMA (anti-ezrin, clone $3 \mathrm{C} 12$ ) and a monoclonal antibody supplied from Calbiochem (antiCD95, clone DX2), respectively.
Immunofluorescence: (i) anti-CD95 polyclonal antibody (Santa Cruz Biotechnology, CA, USA) (ii) anti-ezrin monoclonal antibody (Transduction Laboratories, Lexington, KY, USA).

FACS analysis: anti-CD95-FITC monoclonal antibody (Chemicon International, Inc., CA, USA).

\section{Immunoprecipitation and Western blotting}

Cells were pelleted and lysed in Akt buffer ( $150 \mathrm{~mm}$ Nacl, $20 \mathrm{mM}$ Tris $\mathrm{pH}$ $7.4,1 \%$ NP40, 10\% Glycerol) supplemented with protease and phosphatase inhibitors, incubated for $15 \mathrm{~min}$ on ice and centrifuged for $15 \mathrm{~min}$ at $4^{\circ} \mathrm{C}$, thus removing cell debris and collecting the supernatant.

CD95 and ezrin proteins were immunoprecipitated adding to the precleared lysate $\left(1 \mathrm{~h},+4^{\circ} \mathrm{C}\right)$ the appropriate antibody (see antibodies section) and incubating overnight at $4^{\circ} \mathrm{C}$ in the presence of protein $\mathrm{A}+\mathrm{G}$ sepharose (4B Fast Flow, SIGMA). Immunoprecipitated beads were washed four times in AKT buffer, resuspended in SDS sample buffer and resolved on 10\% SDS-PAGE gel. Immunoprecipitated proteins or total protein extracts were transferred onto nitrocellulose membrane (Schleicher and Schuell) and analyzed by Western blotting, revealing immobilized proteins by ECL detection. Gel stripping was performed using Restore Western blot stripping buffer (Pierce, Rockford, IL, USA), according to the manufacturer's instructions.

\section{Flow cytometry}

\section{Cell cycle analysis}

Cell cycle progression analysis of resting and IL-2-treated T cells was performed by flow cytometry. Cells were fixed and permeabilized with icecold ethanol for $30 \mathrm{~min}$ and, after this time, washed twice with PBS. DNA staining was performed by incubating cells at $37^{\circ} \mathrm{C}$ in PBS containing $40 \mu \mathrm{g} / \mathrm{ml} \mathrm{PI}$ and $0.4 \mathrm{mg} / \mathrm{ml}$ DNase-free RNase (type 1-A). Samples were analyzed collecting FL2 red fluorescence in a linear scale at above $620 \mathrm{~nm}$. The percentage of cells in the different phases of the cell cycle was determined by ModFIT software analysis.

\section{Apoptosis quantification}

Three-color flow cytometric analysis of PBLs was performed before or after CD95 triggering $(500 \mathrm{ng} / \mathrm{ml}$ of IgM anti-CD95 antibody, clone $\mathrm{CH} 11$, upstate Biotechnology, Lake Placid, NY, USA). Cells $\left(5 \times 10^{5}\right)$ were incubated at $4^{\circ} \mathrm{C}$ with a saturating concentration of directly conjugated PerCP-anti-CD4 (BD Biosciences, Mountain View, CA, USA). After $30 \mathrm{~min}$, cells were washed and double stained by using the annexinVisothiocyanate (FITC) apoptosis detection kit (Eppendorf, Milan, Italy). By using this technique, cells that have lost membrane integrity (therefore considered as necrotic cells) will show red staining with PI $(40 \mu \mathrm{g} / \mathrm{ml})$ throughout the nucleus and then they will be easily distinguishable from the living cells.

\section{Quantification of surface antigen expression}

Cells were incubated for $30 \mathrm{~min}$ at $4{ }^{\circ} \mathrm{C}$ with a saturating concentration of the appropriate antibody. After $30 \mathrm{~min}$, cells were washed and incubated at $4^{\circ} \mathrm{C}$ with an FITC-conjugated anti-mouse antibody.

The samples were analyzed with a FACScan cytometer (Becton Dickinson) equipped with a 488 argon laser. At least 20000 events were acquired. Data were recorded and statistically analyzed by a Macintosh computer using CellQuest Software. The calculation of fluorescence (expressed as median value) was carried out after conversion of 
logarithmically amplified signals into values on a linear scale and the statistical significance was calculated by using the parametric Kolmogorov-Smirnov (K/S) test. Statistical analysis of apoptosis data was performed by using Student's $t$-test. All data reported in this paper are the mean of at least four separate experiments \pm standard deviation (S.D.). Only $P$-values of less than 0.01 were considered as significant.

\section{Scanning electron microscopy analysis}

PBLs, grown as described above, were collected by centrifugation and attached to polylysine-coated glass coverslips. Control and treated cells were fixed with $2.5 \%$ glutaraldehyde in $0.1 \mathrm{M}$ cacodylate buffer $(\mathrm{pH} 7.4)$ at room temperature for $20 \mathrm{~min}$. Following postfixation in $0.1 \% \mathrm{OsO}_{4}$ for $30 \mathrm{~min}$, cells were dehydrated through graded ethanols, critical point-dried in $\mathrm{CO}_{2}$ and gold-coated by sputtering. The samples were examined with a Cambridge 360 scanning electron microscope.

\section{Immunofluorescence analysis}

Controls and treated cell surpernatants were collected by centrifugation, attached to polylysine-coated glass coverslips fixed with $4 \%$ paraformaldehyde in PBS for 30 min at room temperature. After washing in the same buffer, cells were permeabilized with $0.5 \%$ Triton X-100 (Sigma) in PBS for $5 \mathrm{~min}$ at room temperature. Samples were then incubated at $37^{\circ} \mathrm{C}$ for $30 \mathrm{~min}$ with the appropriate primary antibody and then with anti-rabbit lgG TRITC-conjugate (whole molecule) or anti-mouse IgG FITC conjugate (whole molecule) (Sigma Chemicals Co., USA). After washing, all samples were mounted with glycerol-PBS (2:1) and analyzed with a Nikon Microphot fluorescence microscope. Images were captured by a colorchilled 3CCD camera (Hamamatsu, Japan). Normalization and background subtraction were performed for each image. Figures were obtained by the OPTILAB (Graftek, France) software for image analysis.

\section{Acknowledgements}

This work was supported by a grant from the Italian Ministry of Health (40/ D.5 National Research Program on AIDS). F Luciani and L Lugini were supported by a fellowship from F.I.R.C.

\section{References}

1. Lynch DH, Ramsdell F and Alderson MR (1995) Fas and FasL in the homeostatic regulation of immune responses. Immunol. Today 16: 569-574

2. Giordano C, Stassi G, De Maria R, Todaro M, Richiusa P, Papoff G, Ruberti G, Bagnasco M, Testi R and Galluzzo A (1997) Potential involvement of Fas and its ligand in the pathogenesis of Hashimoto's thyroiditis. Science 275: 960-963

3. Nagata S (1997) Apoptosis by death factor. Cell 88: 355-365

4. Peter ME and Krammer PH (1998) Mechanisms of CD95 (APO-1/Fas)mediated apoptosis. Curr. Opin. Immunol. 10: 545-551

5. Yang $Y$ and Ashwell JD (2001) Exploiting the apoptotic process for management of HIV: are we there yet? Apoptosis 6: 139-146

6. Roshal M, Zhu Y and Planelles V (2001) Apoptosis in AIDS. Apoptosis 6: 103116

7. Finkel TH, Tudor-Williams G, Banda NK, Cotton MF, Curiel T, Monks C, Baba TW, Ruprecht RM and Kupfer A. (1995) Apoptosis occurs predominantly in bystander cells and not in productively infected cells of HIV-and SIV-infected lymph nodes. Nat. Med. 1: 129-134

8. Ameisen JC and Capron A (1991) Cell dysfunction and depletion in Aids: the programmed cell death hypothesis. Immunol. Today 12: 102-105

9. Katsikis PD, Wunderlich ES, Smith CA, Herzenberg LA and Herzenberg LA (1995) Fas antigen stimulation induces marked apoptosis of T lymphocytes in human immunodeficiency virus-infected individuals. J. Exp. Med. 181: 20292036

10. Estaquier J, Idziorek T, Zou W, Emilie D, Farber CM, Bourez JM and Ameisen JC (1995) Thelper type 1/T helper type 2 cytokines and T cell death: preventive effect of interleukin 12 on activation-induced and CD95 (FAS/APO-1)-mediated apoptosis of $\mathrm{CD} 4+\mathrm{T}$ cells from human immunodeficiency virus-infected persons. J. Exp. Med. 182: 1759-1767

11. Vlahakis SR, Algeciras-Schimnich A, Bou G, Heppelmann CJ, Villasis-Keever A, Collman RC and Paya CV. (2001) Chemokine-receptor activation by env determines the mechanism of death in HIV-infected and uninfected T lymphocytes. J. Clin. Invest. 107: 207-215

12. Klas C, Debatin KM, Jonker RR and Krammer PH (1993) Activation interferes with the APO-1 pathway in mature human T cells. Int. Immunol. 6: 625-630

13. Pearce-Pratt R, Malamud D and Phillips DM (1994) Role of cytoskeleton in cell-to-cell transmission of human immunodeficiency virus. J. Virol. 68: 2898-2905

14. Tuosto L, Gilardini Montani MS, Lorenzetti S, Cundari E, Moretti S, Lombardi G and Piccolella E (1995) Differential susceptibility to monomeric HIV gp120mediated apoptosis in antigen-activated $\mathrm{CD} 4+\mathrm{T}$ cell populations. Eur. J. Immunol. 25: 2907-2916

15. Fais S, Capobianchi MR, Abbate I, Castilletti C, Gentile M, Cordiali Fei P, Ameglio F and Dianzani F (1995) Unidirectional budding of HIV-1 at the site of cell-to-cell contact is associated with co-polarization of intercellular adhesion molecules and HIV-1 viral matrix protein. AIDS 9: 329-335

16. Fais S, Borghi P, Gherardi G, Logozzi M, Belardelli F and Gessani S (1996) Human immunodeficiency virus type 1 induces cellular polarization, intercellular adhesion molecule-1 redistribution, and multinucleated giant cell generation in human primary monocytes but not in monocyte-derived macrophages. Lab. Invest. 75: 783-790

17. Perotti ME, Tan X and Phillips DM (1996) Directional budding of human immunodeficiency virus from monocytes. J. Virol. 70: 5916-5921

18. Accornero P, Radrizzani M, Delia D, Gerosa F, Kurrle R and Colombo MP (1997) Differential susceptibility to HIV-GP120-sensitized apoptosis in CD4+ Tcell clones with different T-helper phenotypes: role of CD95/CD95L interactions. Blood 89: 558-569

19. Iyengar S, Hildreth JK and Schwartz DH (1998) Actin-dependent receptor colocalization required for human immunodeficiency virus entry into host cells. J. Virol. 72: 5251-5255

20. Lapenta C, Boirivant M, Marini M, Santini SM, Logozzi M, Viora M, Belardelli F. and Fais S (1999) Human intestinal lamina propria lymphocytes are naturally permissive to HIV-1 infection. Eur. J. Immunol. 29: 1202-1208

21. Parlato S, Santini SM, Lapenta C, Spada M, Logozzi M, Rizza P, Proietti E, Belardelli $F$ and Fais $S$ (2000b) Primary HIV-1 infection of human CD4+ T cells passaged into SCID mice leads to a selection of chronically infected cells through a massive Fas-mediate autocrine suicide of uninfected cells. Cell Death Differ. 7: 37-47

22. Veazey RS, Marx PA and Lackner AA (2001) The mucosal immune system: primary target for HIV infection and AIDS. Trends Immunol. 22: 626-633

23. Fais $S$ (2002) Importance of the state of activation and/or differentiation of CD4+ T cells in AIDS pathogenesis. Trends Immunol. 23: 128-129

24. Serrador JM, Alonso-Lebrero JL, Del Pozo MA, Furthmayr H, Schwartz-Albiez R, Calvo J, Lozano F and Sanchez-Madrid F (1997) Moesin interacts with the cytoplasmic region of intercellular adhesion molecule-3 and it is redistributed to the uropod of T lymphocytes during cell polarization. J. Cell Biol. 138: 14091423

25. Sanchez-Madrid F and del Pozo MA (1999) Leukocyte polarization in cell migration and immune interactions. EMBO J. 18: 501-511

26. Fais S, Burgio VL, Capobianchi MR, Gessani S, Pallone F and Belardelli $F$ (1997) The biological relevance of polykaryons in the immune response. Immunol. Today 18: 522-527

27. Gomez-Mouton C, Abad JL, Mira E, Lacalle RA, Gallardo E, Jimenez-Baranda S, Illa I, Bernad A, Manes and Martinez AC (2001) Segregation of leading-edge and uropod components into specific lipid rafts during $\mathrm{T}$ cell polarization. Proc. Natl. Acad. Sci. USA 98: 9642-9647

28. Fais $S$ and Malorni W (2003) Leukocyte uropod formation and membrane/ cytoskeleton linkage in immune interactions. J. Leuk. Biol. 73: 556-563

29. Berryman M, Gary R and Bretscher A (1995) Ezrin oligomers are major cytoskeletal components of placental microvilli: a proposal for their involvement in cortical morphogenesis. J. Cell Biol. 131: 1231-1242 
30. Serrador JM, Nieto M, Alonso-Lebrero JL, del Pozo MA, Calvo J, Furthmayr $\mathrm{H}$ Schwartz-Albiez R, Lozano F, Gonzalez-Amaro R, Sanchez-Mateos P and Sanchez-Madrid F (1998) CD43 interacts with moesin and ezrin and regulates its redistribution to the uropods of $\mathrm{T}$ lymphocytes at the cell-cell contacts. Blood 91: 4632-4644

31. Yonemura S, Hirao M, Yoshinori D, Takahashi N, Kondo T, Tsukita S and Tsukita S (1998) Ezrin/radixin/moesin (ERM) proteins binds to positively charged aminoacid cluster in the juxta-membrane cytoplasmic domain of CD44, CD43 and ICAM-2. J. Cell Biol. 140: 885-895

32. Bretscher A (1999) Regulation of cortical structure by the ezrin-radixin-moesin protein family. Curr. Opin. Cell Biol. 11: 109-116

33. Tsukita S and Yonemura S (1999) Cortical actin organization: lessons from ERM (ezrin/radixin/moesin) proteins. J. Biol. Chem. 274: 34507-34510

34. Fais S, Luciani F, Logozzi M, Parlato S and Lozupone F. (2000) Linkage between cell membrane proteins and actin-based cytoskeleton: the cytoskeletal-driven cellular functions. Histol. Histopathol. 15: 539-549

35. Tsukita S, Yonemura S and Tsukita S (1997) ERM proteins: head-to-tail regulation of actin-plasma membrane interaction. Trends Biochem Sci. 22: 5358

36. Gautreau A, Louvard D and Arpin M (2000) Morphogenic effects of ezrin require a phosphorylation-induced transition from oligomers to monomers at the plasma membrane. J. Cell Biol. 150: 193-203

37. Thuillier L, Hivroz C, Fagard R, Andreoli C and Mangeat P (1994) Ligation of CD4 surface antigen induces rapid tyrosine phosphorylation in the cytoskeletal protein ezrin. Cell. Immunol. 156: 322-331

38. Autero M, Heiska L, Ronnstrand L, Vaheri A, Gahmberg CG and Carpen $O$ (2003) Ezrin is a substrate for Lck in T cells. FEBS Lett. 535: 82-86

39. Briand G, Barbeau B and Tremblay M (1997) Binding of HIV-1 to its receptor induces tyrosine phosphorylation of several CD4-associated proteins, including the phosphatidylinositol 3-kinase. Virology 228: 171-179

40. Liu M, Zeng J and Robey FA (1999) Tyrosine phosphorylation induced by CD4 peptide constructs from HIV Gp120. Peptides 20: 185-191

41. Hivroz C, Mazerolles F, Soula M, Fagard R, Graton S, Meloche S, Sekaly RP and Fischer A (1993) Human immunodeficiency virus gp120 and derived peptides activate protein tyrosine kinase p56lck in human CD4T lymphocytes. Eur. J. Immunol. 23: 600-607

42. Roumier A, Olivo-Marin JC, Arpin M, Michel F, Martin M, Mangeat $P$, Acuto O, Dautry-Varsat A and Alcover A (2001) The membrane-microfilament linker ezrin is involved in the formation of the immunological synapse and in T cell activation. Immunity 15: 715-728

43. Parlato S, Giammarioli A, Logozzi M, Lozupone F, Matarrese $P$, Luciani $F$, Falchi M, Malorni W and Fais S (2000a) CD95 (APO1/Fas) linkage to the actin cytoskeleton through ezrin in human T-lymphocytes: a novel regulatory mechanism of the CD95 apoptotic pathway. EMBO J. 19: 5123-5134

44. Algeciras-Schimnich A, Shen L, Barnhart BC, Murmann AE, Burkhardt JK and Pete ME (2002) Molecular ordering of the initial signaling events of CD95. Mol. Cell Biol. 22: 207-220

45. Algeciras A, Dockrell DH, Lynch DH and Paya CV (1998) CD4 regulates susceptibility to Fas ligand- and TNF-mediated apoptosis. J. Exp. Med. 187: $711-720$

46. Wajant $H$ (2002) The Fas signaling pathway: more than a paradigm. Science 296: $1635-1636$

47. Cloyd MW, Chen JJ, Adeqboyega P and Wang L (2001) How does HIV cause depletion of CD4 lymphocytes? A mechanism involving virus signaling through its cellular receptors. Curr. Mol. Med. 1: 545

48. Selliah N and Finkel TH (2001) Biochemical mechanism of HIV induced T cell apoptosis. Cell Death Differ. 8: 127-136

49. Bretscher A (1989) Rapid phosphorylation and reorganization of ezrin and spectrin accompany morphological changes induced in A-431 cells by epidermal growth factor. Cell. Biol. 108: 921-930

50. Krieg $\mathrm{J}$ and Hunter $\mathrm{T}$ (1992) Identification of the two major epidermal growth factor-induced tyrosine phosphorylation sites in the microvillar core protein ezrin. J. Biol. Chem. 267: 19258-19265

51. Crepaldi T, Gautreau A, Comoglio PM, Louvard D and Arpin M (1997) Ezrin is an effector of hepatocyte growth factor-mediated migration and morphogenesis in epithelial cells. J. Cell Biol. 138: 423-434

52. Gautreau A, Poullet P, Louvard D and Arpin M (1999) Ezrin, a plasma membrane-microfilament linker, signals cell survival through the phosphatidylinositol 3-kinase/Akt pathway. Proc. Natl. Acad. Sci. USA 96: 7300-7305

53. Perez OD, Kinoshita S, Hitoshi Y, Payan DG, Kitamura T, Nolan GP and Lorens JB (2002) Activation of the PKB/AKT pathway by ICAM-2. Immunity 16: 51-65

54. Siliciano RF (1996) The role of CD4 in HIV envelope-mediated pathogenesis. Curr. Top. Microbiol. Immunol. 205: 159-179

55. Westendorp MO, Frank R, Ochsenbauer C, Stricker K, Dhein J, Walczak H, Debatin KM and Krammer PH (1995) Sensitization of T cells to CD95-mediated apoptosis by HIV-1 Tat and gp120. Nature 375: 497-500

56. Banda NK, Bernier J, Kurahara DK, Kurrle R, Haigwood N, Sekaly RP and Finkel TH (1992) Crosslinking CD4 by human immunodeficiency virus gp120 primes T cells for activation-induced apoptosis. J. Exp. Med. 176: 1099-1106

57. Sousa AE, Carneiro J, Meier-Schellersheim M, Grossman Z and Victorino RMM (2002) CD4T cell depletion is linked directly to immune activation in the pathogenesis of HIV-1 and HIV-2 but only indirectly to the viral load. J. Immunol. 169: 3400-3406 